\title{
Inadequate dietary energy intake associates with higher prevalence of metabolic syndrome in different groups of hemodialysis patients: a clinical observational study in multiple dialysis centers
}

Tuyen Van Duong', Te-Chih Wong ${ }^{2}$, Hsi-Hsien Chen ${ }^{3,4}$, Tzen-Wen Chen ${ }^{4}$, Tso-Hsiao Chen ${ }^{4,5}$, Yung-Ho Hsu ${ }^{4,6}$, Sheng-Jeng Peng ${ }^{7}$, Ko-Lin Kuo ${ }^{8}$, Hsiang-Chung Liu ${ }^{9}$, En-Tzu Lin ${ }^{10}$, Chi-Sin Wang ${ }^{1}$, I-Hsin Tseng ${ }^{1}$, Yi-Wei Feng ${ }^{1}$, Tai-Yue Chang ${ }^{1}$, Chien-Tien Su ${ }^{11,12}$ and Shwu-Huey Yang ${ }^{1,13,14^{*}}$ (D)

\begin{abstract}
Background: Metabolic syndrome (MetS) has been established as a risk for cardiovascular diseases and mortality in hemodialysis patients. Energy intake (EI) is an important nutritional therapy for preventing MetS. We examined the association of self-reported dietary El with metabolic abnormalities and MetS among hemodialysis patients.

Methods: A cross-sectional study design was carried out from September 2013 to April 2017 in seven hemodialysis centers. Data were collected from 228 hemodialysis patients with acceptable El report, 20 years old and above, underwent three hemodialysis sessions a week for at least past 3 months. Dietary El was evaluated by a three-day dietary record, and confirmed by 24-h dietary recall. Body compositions were measured by bioelectrical impedance analysis. Biochemical data were analyzed using standard laboratory tests. The cut-off values of daily El were $30 \mathrm{kcal} / \mathrm{kg}$, and $35 \mathrm{kcal} / \mathrm{kg}$ for age $\geq 60$ years and $<60$ years, respectively. MetS was defined by the American Association of Clinical Endocrinologists (AACE-MetS), and Harmonizing Metabolic Syndrome (HMetS). Logistic regression models were utilized for examining the association between El and MetS. Age, gender, physical activity, hemodialysis vintage, Charlson comorbidity index, high sensitive C-reactive protein, and interdialytic weight gains were adjusted in the multivariate analysis.

\footnotetext{
* Correspondence: sherry@tmu.edu.tw

${ }^{1}$ School of Nutrition and Health Sciences, Taipei Medical University, No. 250

Wuxing Street, Taipei 110, Taiwan

${ }^{13}$ Research Center of Geriatric Nutrition, Taipei Medical University, Taipei,

Taiwan

Full list of author information is available at the end of the article
}

C The Author(s). 2018 Open Access This article is distributed under the terms of the Creative Commons Attribution 4.0 International License (http://creativecommons.org/licenses/by/4.0/), which permits unrestricted use, distribution, and reproduction in any medium, provided you give appropriate credit to the original author(s) and the source, provide a link to the Creative Commons license, and indicate if changes were made. The Creative Commons Public Domain Dedication waiver (http://creativecommons.org/publicdomain/zero/1.0/) applies to the data made available in this article, unless otherwise stated. 


\begin{abstract}
(Continued from previous page)
Results: The prevalence of inadequate El, AACE-MetS, and HMetS were $60.5 \%, 63.2 \%$, and $53.9 \%$, respectively. Inadequate El was related to higher proportion of metabolic abnormalities and MetS $(p<0.05)$. Results of the multivariate analysis shows that inadequate El was significantly linked with higher prevalence of impaired fasting glucose $(\mathrm{OR}=2.42, p<0.01)$, overweight/obese $(\mathrm{OR}=6.70, p<0.001)$, elevated waist circumference $(\mathrm{OR}=8.17, p<0$. 001), AACE-MetS $(\mathrm{OR}=2.26, p<0.01)$, and HMetS $(\mathrm{OR}=3.52, p<0.01)$. In subgroup anslysis, inadequate El strongly associated with AACE-MetS in groups of non-hypertension ( $\mathrm{OR}=4.09, p=0.004)$, and non-cardiovascular diseases (OR $=2.59, p=0.012)$, and with HMetS in all sub-groups of hypertension $(\mathrm{OR}=2.59 \sim 5.33, p<0.05)$, diabetic group $(\mathrm{OR}=8$. $33, p=0.003)$, and non-cardiovascular diseases $(\mathrm{OR}=3.79, p<0.001)$.
\end{abstract}

Conclusions: Inadequate El and MetS prevalence was high. Energy intake strongly determined MetS in different groups of hemodialysis patients.

Keywords: Hemodialysis patients, Inadequate dietary energy intake, Metabolic syndrome, AACE, HMetS

\section{Introduction}

The prevalence of treated end-stage renal disease (ESRD) has steadily increased from 2001 to 2014 in all countries, and become a burden to every nation and healthcare system [1]. In 2014, the prevalence of ESRD patients undergoing dialysis in Taiwan was 3093 patients per million population, about $90 \%$ of them receiving in-center hemodialysis treatment [1]. It was summarized that nutritional factor was implicated as a risk factor for the development of metabolic in chronic kidney disease, especially in ESRD patients [2].

Nutritional therapy is recognized as an effective approach to prevent metabolic abnormalities and unfavorable outcomes in people with chronic conditions [3-8]. Increased dietary energy intake is mentioned in the National Kidney Foundation-Kidney Disease Outcomes Quality Initiative (K/DOQI) guidelines [9]. It is recommended that consuming enough energy daily guarantees the nitrogen balance and prevents protein catabolism and tissue destruction, which could optimize the nutritional status and hemodialysis outcomes [9]. However, the daily intake of macro-nutrients and micro-nutrients are largely inadequate in hemodialysis patients [10]. More than a half of hemodialysis patients had problems to follow the healthy diet guidelines (related to energy and nutrients intakes) which related behaviors, technical difficulties, physical conditions, time, and food preparation [11]. Inadequate dietary intake is also a possible result of a significant lifestyle change while receiving dialysis treatment. On the other hand, adherence to a complicated and restrictive dietary intake further exacerbates nutrient deficits in this group of patients [9, 12-14].

The prevalence of metabolic syndrome was high in the ESRD patients undergoing hemodialysis [15]. The MetS has been implicated as a risk factor for the development of diabetes, cardiovascular disease, cancer, and all-cause mortality [16-19]. The prevalence of metabolic syndrome varied by different assessment criteria, e.g. 51\%, $66.3 \%$, and $75.3 \%$ according to National Cholesterol
Education Program Adult Treatment Panel III (NCEP ATP III), International Diabetes Federation (IDF), and Harmonizing the Metabolic Syndrome (HMetS) criteria, respectively [20]. This indicated that there was not yet a single definition that could reflect the real spectrum of the epidemiology of MetS. Therefore, in the current study, two definitions were used with different focuses to assess the MetS: The American Association of Clinical Endocrinologists (AACE) definition, focused on hyperglycosemia, was glucocentric [21]; and Harmonizing Metabolic Syndrome definition was agreed by Joint statement from the IDF, American Heart Association (AHA) and the National Heart, Lung, and Blood Institute (NHLBI), the World Heart Federation, the International Atherosclerosis Society, and the International Association for the Study of Obesity, which relayed on collection of abdominal obesity and related CVD risk factors [22].

There were few studies investigated dietary intake among hemodialysis patients. One study compared the dietary intake status between $54 \mathrm{HD}$ patients, and 47 non-HD patients, and between dialysis day and non-dialysis day among elderly people in Brazil [23]. The other study in the United States only examined the association between dietary energy intake and body composition changes in $13 \mathrm{HD}$ patients [24]. In addition, the dietary approach was found as an effective therapy to decrease most of the risks for MetS in a randomized controlled trial [25]. However, hemodialysis patients were with high metabolic syndrome prevalence, and generally have difficulties achieving recommended energy intakes. In our knowledge, the role of dietary energy intake on metabolic disorders among hemodialysis patients remains to be investigated.

This study was to examine the association of inadequate dietary energy intake with metabolic abnormalities and metabolic syndrome among patients who receiving hemodialysis treatment from seven hemodialysis centers. It was hypothesized that hemodialysis patients with reported 
inadequate dietary energy intake (IDEI) more likely had metabolic abnormalities or metabolic syndrome.

\section{Methods}

\section{Study design and setting}

A cross-sectional study design was carried out from September 2013 to April 2017. We collected data from 492 patients from hemodialysis centers in seven hospitals. The study sample consisted 165 from Taipei Medical University Hospital, 91 from Taipei Medical University - Wan Fang Hospital, 39 from Taipei Medical University Shuang Ho Hospital, 41 from Cathay General Hospital, 57 from Taipei Tzu-Chi Hospital, 49 from Wei-Gong Memorial Hospital, and 50 from Lotung Poh-Ai Hospital.

\section{Sample size}

The sample size in a cross-sectional design is calculated using the formula: $n=\frac{Z^{2} P(1-P)}{d^{2}}$ Where $n$ (sample size), $Z$ (level of confidence), $P$ (expected prevalence), and $d$ (precision, corresponding to effect size) [26]. The sample of 92 was calculated with $Z=1.96$ for type I error of $5 \%, P=$ 0.745 as the prevalence of MetS was $74.5 \%$ in hemodialysis patients [27], and $d=0.1$ as suggested for a medical study [28]. In the current study, the final sample of 228 patients is adequate for analysis and depicted in Fig. 1.

\section{Patient recruitment criteria}

The study patients in the current study fulfilled the recruitment criteria as mentioned elsewhere [29-31].

\section{Data collection procedure}

The physicians and nurses in each hospital screened for qualified patients who satisfied the recruitment criteria. The interviewers (Registered Dietitians) then contacted the eligible patients and asked for their voluntary participation.

The eligible patients signed the informed consent form before participating in the face-to-face or telephone interviews which conducted by registered dietitians (three-day dietary intake, physical activity). The medical charts were reviewed after the interviews. Anthropometric, and energy expenditure values were also measured. Licensed nurses collected blood samples at the first dialysis session during the study week, biochemical data was then analyzed using available laboratory test kits, the procedure was described in details elsewhere [32].

\section{Measures}

\section{Patients' characteristics}

The information regarding age, gender, hemodialysis vintage, comorbidities calculated using the Charlson comorbidity index [33], history of hypertension, cardiovascular diseases, and type 2 diabetes mellitus (T2DM), body mass index, BMI $\left(\mathrm{kg} / \mathrm{m}^{2}\right)$, pre-dialysis systolic (SBP) and diastolic (DBP) blood pressure were also assessed using medical records. The waist circumference (WC), body fat mass (FM) were assessed using the bio-electrical impedance analysis device (InBody S10, Biospace, Seoul, Korea), the detailed procedure was described elsewhere [34]. Elevated body fat mass was defined as $\mathrm{FM} \geq 25 \%$ for men, $\mathrm{FM} \geq 30 \%$ for women, respectively [35]. Interdialytic

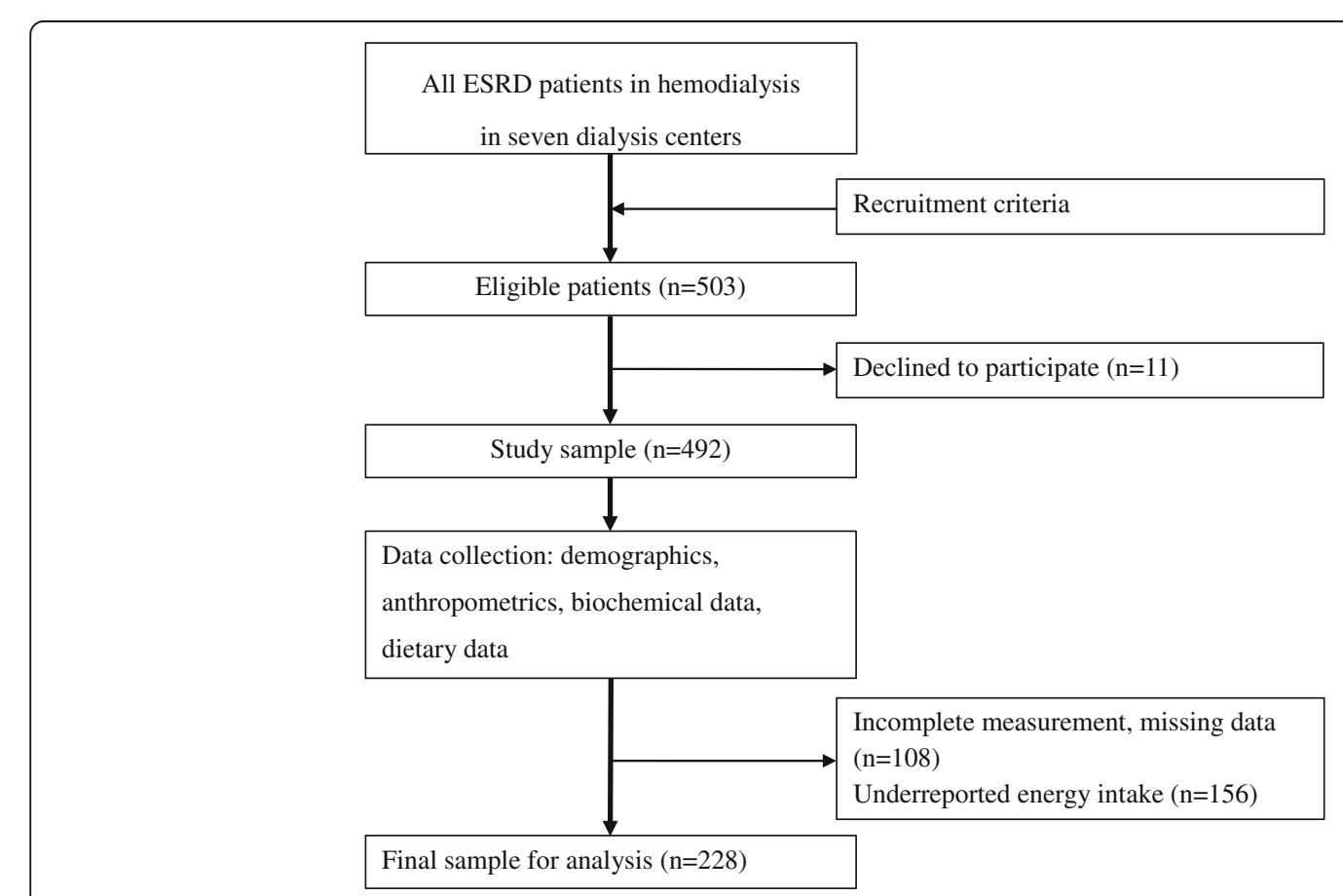

Fig. 1 Flow chart of patients sampling and study procedure. ESRD: End-stage renal disease 
weight gains (IDWG) was also calculated. Higher IDWG linked with higher BP in hemodialysis patients [36].

\section{Physical activity}

The short version of the International Physical Activity Questionnaire was used to evaluate physical activity level. Patients were asked about their time spent (days per week, and minutes per day) on different levels of physical intensity (vigorous, moderate, walking, and sitting), questionnaire took 4 to $15 \mathrm{~min}$ to complete [37]. The overall physical activity score was calculated as the sum of minutes spent on activities at different levels of vigorous, moderate, walking, and sitting over last seven days multiplied by $8.0,4.0$, and 3.3, 1.0, respectively [38]. The common method using metabolic equivalent task scored in minute per week (named as MET- min/wk) was used to represent the physical activity [39].

\section{Dietary energy intake}

We used three-day dietary intake record to assess patient's intake, and confirmed data by a 24-h dietary recall, the details were mentioned elsewhere [32, 40]. In brief, the information related to names of food, brand, ingredients, cooking methods, portion or weight, meal location and time were collected. The e-Kitchen software, a nutrient analysis software (Nutritionist Edition, Enhancement plus 3, version 2009, Taichung, Taiwan) was used for analyzing nutrients.

The recommended daily dietary energy intake was $\geq 35 \mathrm{kcal} / \mathrm{kg}$ for patients younger than 60 years old, and $\geq$ $30 \mathrm{kcal} / \mathrm{kg}$ for those who 60 years old or older, respectively [9]. Inadequate dietary energy intake was defined as patients consumed less than the recommended levels. In order to enhance the reliability of measures and analysis, the under-reported dietary energy intake (EI) data were excluded from the final analysis if the ratio of EI:REE < 1.27 [41]. The results of the analysis were not affected by excluding the under-reporters in the study [42]. The resting energy expenditure (REE) was assessed using a hand-held indirect calorimeter, named MedGem (Microlife USA, Dunedin, FL). A modified Weir equation together with a fixed respiratory exchange ratio of 0.85 were used to estimate carbon dioxide production. Patients wore a nose clip and a mouthpiece, then breathe normally for about 7-10 min, or until the volume of oxygen is stable. The MedGem has been validated against several metabolic calorimeters such as Douglas Bag method [43], and metabolic cart systems [44, 45]. This device has the similar accuracy of commonly used prediction equations such as the WHO/FAU/UNU, Mifflin, or Harris-Benedict equations [46], and used in hemodialysis patients [47].

\section{The biochemical values}

Fasting blood glucose (FPG), fasting plasma insulin (FPI), total cholesterol (TC), triglyceride (TG), high-density lipoprotein cholesterol (HDL-C), low-density lipoprotein cholesterol (LDL-C), high sensitive C-reactive protein (hs-CRP), Creatinine, Albumin, intact parathyroid hormone (iPTH), the normalized protein nitrogen appearance (nPNA) was estimated using the formula: nPNA $=$ Pre-BUN $/[25.8+$ $1.15 *(\mathrm{eKt} / \mathrm{V})+56.4 /(\mathrm{eKt} / \mathrm{V})]+0.168$, where pre-BUN is pre-dialysis blood urea nitrogen $(\mathrm{mg} / \mathrm{dL})$, post-BUN is post-dialysis blood urea nitrogen $(\mathrm{mg} / \mathrm{dl})$, and equilibrated $\mathrm{Kt} / \mathrm{V}$ is dialysis quality [48].

\section{Diagnosis of metabolic syndrome (MetS)}

The MetS was classified by American Association of Clinical Endocrinologists (AACE), hereafter referred as AACE-MetS [21]. Patients were identified as MetS if they had (1) and any of the criteria (2), or (3), or (4). (1) Impaired fasting glucose (IFG) which patients had FPG $\geq$ $100 \mathrm{mg} / \mathrm{dL}$, or previously diagnosed T2DM [49]. (2) Overweight or obese (BMI $\geq 24.0 \mathrm{~kg} / \mathrm{m}^{2}$ for Taiwanese) [50]. (3) $\mathrm{TG} \geq 150 \mathrm{mg} / \mathrm{dL}, \mathrm{HDL}-\mathrm{C}<40 \mathrm{mg} / \mathrm{dL}$ for men or HDL-C $<50 \mathrm{mg} / \mathrm{dL}$ for women. (4) $\mathrm{SBP} \geq 130 \mathrm{mmHg}$ or $\mathrm{DBP} \geq 85 \mathrm{mmHg}$.

To affirm the non-spurious association, the Harmonizing Metabolic Syndrome definition (HMetS) was also used to evaluate MetS. Patients were classified as MetS if they have three or more abnormalities $(W C \geq 90 \mathrm{~cm}$ for men, WC $\geq 80 \mathrm{~cm}$ for women, $\mathrm{TG} \geq 150 \mathrm{mg} / \mathrm{dL}$, low HDL-C, high BP, or IFG) [22].

\section{Other biochemical value classifications}

The lipid profile (LDL-C $\geq 100 \mathrm{mg} / \mathrm{dL}$, and $\mathrm{TC} \geq 200 \mathrm{mg} /$ dL) [51], inflammation maker (high sensitive-CRP > $0.5 \mathrm{mg} / \mathrm{dL}$ ) [52], elevated insulin (FPI $\geq 12 \mathrm{mU} / \mathrm{L}$ ) [53, 54], $\mathrm{iPTH} \geq 300 \mathrm{pg} / \mathrm{mL}$ [55]. In addition, the poor nutritional status including nPNA $<1.0 \mathrm{~g} / \mathrm{kg}$, serum albumin $(\mathrm{Alb}) \leq$ $3.5 \mathrm{mg} / \mathrm{dL}$, and serum creatinine $(\mathrm{Cr}) \leq 7.5 \mathrm{mg} / \mathrm{dL}$ [56].

\section{Statistical analysis}

The study sample was described using mean \pm standard deviation (SD), or median (interquartile range), or frequency (percentage). The continuous variables were tested for normality by using a Shapiro-Wilk's test $[57,58]$, and histograms, box plots, and normal Q-Q plots were examined. The ANOVA, Mann-Whitney U test, or Chi-Square test were recruited in order to compare characteristics and metabolic parameters of the adequate and inadequate EI groups. The bivariate logistic regression models were recruited for examining associations of patients' characteristics, dietary intake with metabolic abnormalities and MetS. The multivariate logistic regression analyses were then utilized for examining the association of inadequate dietary intake of nutrients with metabolic abnormalities 
and MetS. The sub-group analyses were performed in different groups of diabetes mellitus, hypertension, and cardiovascular diseases. Patients' gender, age, physical activity, hemodialysis vintage, Charlson comorbidity index (CCI), hs-CRP, and IDWG were controlled in the multivariate analyses as they showed the associations with metabolic syndrome [59-63]. The analyses were performed for both diagnosed criteria of MetS (AACE-MetS and H-MetS) to affirm the non-spurious association. The IBM SPSS software version 20.0 for Windows (IBM Corp., New York, USA) was used for all analyses. The statistically significant level was set at $P$ value $<0.05$.

\section{Results}

The mean \pm SD of age, hemodialysis vintage, physical activity, CCI, and interdialytic weight gains were $59.4 \pm$ $11.3,5.5 \pm 5.0,4831.3 \pm 1893.1,4.6 \pm 1.5$, and $3.0 \pm 1.7$, respectively. Of study sample, there were $64.9 \%$ men, $38.2 \%$ diabetes, $48.2 \%$ hypertension, and $29.8 \%$ cardiovascular diseases, $28.5 \%$ with an elevated level of hs-CRP, $54.5 \%$ elevated body fat mass. The REE was lower in patients with inadequate EI $(1014.5 \pm 280.4)$ than those with adequate EI $(1100.9 \pm 274.7)$, with $p=$ 0.023. Regarding metabolic abnormalities, the prevalence of IFG, overweight or obese, elevated WC, high BP, high TG, and low HDL-C were $64.9 \%, 36.4 \%, 26.3 \%, 81.6 \%$, $39.0 \%$, and $61.0 \%$, respectively. The prevalence of metabolic syndrome was $63.2 \%$ as diagnosed by AACE criteria, and $53.9 \%$ as diagnosed by HMetS criteria. The prevalence of the metabolic abnormalities (not hypertension) and syndromes were statistically significantly higher in hemodialysis patients with inadequate EI than those who with adequate EI (Table 1). Out of patients, $60.5 \%$ reported less than the recommendation level of dietary energy intake. Patients with inadequate EI more likely consumed inadequate protein and fat, but consumed less mineral, water, and vitamin than those with adequate EI (Table 2).

The results of bivariate logistic regression analyses presented that higher age associated with higher prevalence of IFG and AACE-MetS with odd ratio, $\mathrm{OR}=1.03$, 95\% confidence interval, 95\%CI, 1.00-1.05, $p<0.05$, and $\mathrm{OR}=1.03,95 \% \mathrm{CI}, 1.01-1.06, p<0.05$, respectively. Men experienced higher prevalence of overweight or obesity $(\mathrm{OR}=1.85,95 \% \mathrm{CI}, 1.03-3.33, p<0.05)$, but lower prevalence of elevated waist circumference $(\mathrm{OR}=0.32$, $95 \% \mathrm{CI}, 0.17-0.59, p<0.001)$ than women. Hemodialysis vintage was negatively associated with IFG $(\mathrm{OR}=0.91$, 95\%CI, 0.86-0.97, $p<0.001$ ), Overweight/obese (OR = 0.92, 95\% CI, 0.86-0.98, $p<0.05)$, high TG ( $\mathrm{OR}=0.94$, 95\%CI, 0.89-0.99, $p<0.05)$, low HDL-C (OR $=0.95$, 95\%CI, 0.90-0.99, $p<0.05)$, AACE-MetS (OR $=0.90$, 95\%CI, 0.85-0.96, $p<0.001)$, and HMetS (OR $=0.94$, 95\%CI, 0.89-0.99, $p<0.05)$, respectively. Charlson comorbidity index was positively associated with IFG (OR $=1.38,95 \% \mathrm{CI}, 1.14-1.67, p<0.001)$, Overweight $/$ obese $(\mathrm{OR}=1.21,95 \% \mathrm{CI}, 1.01-1.45, p<0.05)$, AACE-MetS $(\mathrm{OR}=1.44,95 \% \mathrm{CI}, 1.19-1.74, p<0.001)$, and HMetS $(\mathrm{OR}=1.28,95 \% \mathrm{CI}, 1.07-1.53, p<0.01)$, respectively. Interdialytic weight gains was positively linked with IFG $(\mathrm{OR}=1.21,95 \% \mathrm{CI}, 1.03-1.43, p<0.05)$, AACE-MetS $(\mathrm{OR}=1.22,95 \% \mathrm{CI}, 1.04-1.43, p<0.05)$, and HMetS (OR $=1.24,95 \% \mathrm{CI}, 1.06-1.46, p<0.01)$, respectively (Table 3 ).

Reported inadequate dietary energy intake associated with 1.83-6.20 folds of metabolic abnormalities or metabolic syndrome. It was significantly linked to higher prevalence of IFG $(\mathrm{OR}=2.50,95 \% \mathrm{CI}, 1.43-4.37, p<0.001)$, overweight/obese $\quad(\mathrm{OR}=6.10,95 \% \mathrm{CI}, 3.10-11.99, \quad p$ $<0.001)$, elevated waist circumference $(\mathrm{OR}=6.20,2.78$ 13.84, $p<0.001)$, high triglyceride $(\mathrm{OR}=1.90,95 \% \mathrm{CI}$, $1.09-3.34, p<0.05)$, low HDL-C $(\mathrm{OR}=1.83,95 \% \mathrm{CI}$, $1.06-3.15, p<0.05)$, AACE -MetS $(\mathrm{OR}=2.34,95 \% \mathrm{CI}$, $1.35-4.06, p<0.01$ ), and HMetS (OR $=3.24,95 \% \mathrm{CI}$, $1.86-5.63, p<0.001)$, respectively. The sodium and fluid intake were not associated with metabolic abnormalities or MetS (Table 3).

The associations of inadequate energy intake with metabolic abnormalities, AACE-MetS, and HMetS were stronger by 2.26 to 8.17 folds after adjusted for gender, age, physical activity, hemodialysis vintage, Charlson comorbidity index (CCI), hs-CRP, and IDWG in multivariate analyses. Inadequate energy intake did not show the significant association with high TG, low HDL-C or high blood pressure (Table 4). On the other hand, the consumption of MUFA greater or equal to $20 \%$ of EI is associated with higher likelihood of having IFG $(\mathrm{OR}=2.85$, 95\%CI, 1.39-5.87, $p<0.01$ ), and AACE-MetS (OR = 3.01, 95\%CI, 1.45-6.26, $p<0.01$, Table 4).

In sub-group analyses, inadequate EI showed an significant association with higher prevalence of AACE-MetS in non-hypertension group ( $\mathrm{OR}=4.09,95 \% \mathrm{CI}, 1.55-10.77, p$ $=0.004)$, and non-cardiovascular disease group $(\mathrm{OR}=$ 2.59, 95\% CI, 1.23-5.42, $p=0.012$ ); and associated with HMetS in group of diabetes $(\mathrm{OR}=8.33,95 \% \mathrm{CI}, 2.08$ 33.37, $p=0.003)$, non-hypertension $(\mathrm{OR}=5.33,95 \% \mathrm{CI}$, 1.97-14.40, $p=0.001)$, hypertension $(\mathrm{OR}=2.59,95 \% \mathrm{CI}$, $1.05-6.37, p=0.038)$, and non-CVD $(\mathrm{OR}=3.79,95 \% \mathrm{CI}$, $1.80-7.97, p<0.001$, Table 5).

\section{Discussion}

In the present study, results elucidated that reported inadequate dietary energy intake (IDEI) associated with more MetS abnormalities, and a higher proportion of MetS. The reported IDEI strongly determined 2.26 to 8.17 folds of metabolic abnormalities and MetS diagnosed either by AACE or HMetS criteria. In hemodialysis patients, IDEI disrupts the energy balance, and the nitrogen balance, increases the tissue destruction, and protein catabolism 
Table 1 Characteristics, and metabolic parameters, and other biochemical values in hemodialysis patients ${ }^{a}$

\begin{tabular}{|c|c|c|c|c|}
\hline Variables & Total sample $(n=228)$ & Adequate El $(n=90)$ & Inadequate El $(n=138)^{\mathrm{b}}$ & $P$ value ${ }^{c}$ \\
\hline \multicolumn{5}{|l|}{ Characteristics } \\
\hline Age, years & $59.4 \pm 11.3$ & $59.9 \pm 10.8$ & $59.1 \pm 11.6$ & 0.630 \\
\hline Gender, male & $148(64.9)$ & $57(63.3)$ & $91(65.9)$ & 0.687 \\
\hline Hemodialysis vintage, years & $5.5 \pm 5.0$ & $6.9 \pm 5.9$ & $4.5 \pm 4.0$ & $<0.001$ \\
\hline $\mathrm{CCl}$ & $4.6 \pm 1.5$ & $4.7 \pm 1.5$ & $4.5 \pm 1.6$ & 0.327 \\
\hline Diabetes mellitus & $87(38.2)$ & $24(26.7)$ & $63(45.7)$ & 0.004 \\
\hline Hypertension & $110(48.2)$ & $45(50.0)$ & $65(47.1)$ & 0.669 \\
\hline Cardiovascular diseases & $68(29.8)$ & $26(28.9)$ & $42(30.4)$ & 0.803 \\
\hline Physical activity, MET score & $4831.3 \pm 1893.1$ & $4984.9 \pm 2033.2$ & $4732.6 \pm 1798.1$ & 0.330 \\
\hline Height, cm & $162.4 \pm 8.3$ & $161.4 \pm 7.0$ & $163.0 \pm 9.0$ & 0.149 \\
\hline Weight, kg & $61.4 \pm 12.3$ & $55.1 \pm 8.9$ & $65.4 \pm 12.6$ & 0.000 \\
\hline IDWG, \% & $3.0 \pm 1.7$ & $2.9 \pm 2.0$ & $3.1 \pm 1.5$ & 0.227 \\
\hline $\mathrm{FM}, \%$ & $27.2 \pm 10.0$ & $23.4 \pm 9.1$ & $29.7 \pm 9.9$ & $<0.001$ \\
\hline Elevated FM & $122(54.5)$ & $34(38.2)$ & $88(65.2)$ & $<0.001$ \\
\hline REE, kcal/day & $1048.6 \pm 280.8$ & $1100.9 \pm 274.7$ & $1014.5 \pm 280.4$ & 0.023 \\
\hline \multicolumn{5}{|l|}{ Metabolic abnormalities } \\
\hline FPG & $105.3(90.5,145.2)$ & $97.3(90.3,134.0)$ & $114.0(93.6,153.8)$ & 0.025 \\
\hline IFG & $148(64.9)$ & $47(52.2)$ & $101(73.2)$ & 0.001 \\
\hline $\mathrm{BMI}, \mathrm{kg} / \mathrm{m}^{2}$ & $23.2 \pm 3.8$ & $21.1 \pm 2.6$ & $24.5 \pm 3.9$ & $<0.001$ \\
\hline $\mathrm{BMI} \geq 24\left(\mathrm{~kg} / \mathrm{m}^{2}\right)$ & $83(36.4)$ & $13(14.4)$ & $70(50.7)$ & $<0.001$ \\
\hline$W C, \mathrm{~cm}$ & $81.1 \pm 10.4$ & $75.7 \pm 7.5$ & $87.6 \pm 36.4$ & 0.002 \\
\hline Elevated WC & $60(26.3)$ & $8(8.9)$ & $52(37.7)$ & $<0.001$ \\
\hline $\mathrm{TG}, \mathrm{mg} / \mathrm{dL}$ & $115.0(82.9,202.6)$ & $99.1(78.0,155.4)$ & $136.8(85.0,250.5)$ & 0.004 \\
\hline High TG $\geq 150$ (mg/dL) & $89(39.0)$ & $27(30.0)$ & $62(44.9)$ & 0.024 \\
\hline $\mathrm{HDL}-\mathrm{C}, \mathrm{mg} / \mathrm{dL}$ & $41.6 \pm 22.1$ & $45.8 \pm 21.0$ & $38.9 \pm 22.4$ & 0.021 \\
\hline Low HDL-C & $139(61.0)$ & $47(52.2)$ & $92(66.7)$ & 0.029 \\
\hline $\mathrm{SBP}, \mathrm{mmHg}$ & $146.5 \pm 22.7$ & $149.5 \pm 24.0$ & $144.3 \pm 21.3$ & 0.089 \\
\hline $\mathrm{DBP}, \mathrm{mmHg}$ & $80.0 \pm 18.2$ & $79.8 \pm 19.0$ & $79.9 \pm 17.6$ & 0.959 \\
\hline High BP & $186(81.6)$ & $73(81.1)$ & $113(81.9)$ & 0.883 \\
\hline AACE-MetS ${ }^{d}$ & $144(63.2)$ & $46(51.1)$ & $98(71.0)$ & 0.002 \\
\hline HMetS $^{e}$ & $123(53.9)$ & $33(36.7)$ & $90(65.2)$ & $<0.001$ \\
\hline \multicolumn{5}{|l|}{ Other biochemical values } \\
\hline $\mathrm{TC}, \mathrm{mg} / \mathrm{dL}$ & $168.3 \pm 37.9$ & $163.8 \pm 33.7$ & $170.7 \pm 40.0$ & 0.178 \\
\hline $\mathrm{TC} \geq 200 \mathrm{mg} / \mathrm{dL}$ & $39(17.1)$ & $10(11.1)$ & $29(21.0)$ & 0.052 \\
\hline $\mathrm{LDL}-\mathrm{C}, \mathrm{mg} / \mathrm{dL}$ & $102.1 \pm 32.5$ & $98.0 \pm 31.0$ & $104.6 \pm 32.9$ & 0.130 \\
\hline $\mathrm{LDL}-\mathrm{C} \geq 100 \mathrm{mg} / \mathrm{dL}$ & $41(18.0)$ & $13(14.4)$ & $28(20.3)$ & 0.261 \\
\hline $\mathrm{FPI}, \mu \mathrm{U} / \mathrm{mL}$ & $15.2(7.9,31.9)$ & $12.7(6.8,26.5)$ & $18.6(9.3,35.7)$ & 0.004 \\
\hline $\mathrm{FPI} \geq 12 \mu \mathrm{U} / \mathrm{mL}$ & $142(62.3)$ & $47(52.2)$ & $95(68.8)$ & 0.011 \\
\hline hs-CRP, mg/dL & $0.3(0.1,0.6)$ & $0.2(0.1,0.5)$ & $0.3(0.1,0.6)$ & 0.277 \\
\hline hs-CRP $\geq 0.5 \mathrm{mg} / \mathrm{dL}$ & $65(28.5)$ & 23 (25.6) & $42(30.4)$ & 0.425 \\
\hline iPTH, pg/mL & $225.2(80.6,409.1)$ & $231.0(68.5,441.2)$ & $223.9(94.4,382.7)$ & 0.916 \\
\hline iPTH $\geq 300$ pg/mL & $93(40.8)$ & $38(42.2)$ & $55(39.9)$ & 0.722 \\
\hline Creatinine, mg/dL & $11.1 \pm 1.9$ & $10.8 \pm 1.7$ & $11.3 \pm 2.1$ & 0.077 \\
\hline Creatinine $\leq 7.5 \mathrm{mg} / \mathrm{dL}$ & $8(3.5)$ & $6(6.7)$ & $2(1.4)$ & 0.036 \\
\hline
\end{tabular}


Table 1 Characteristics, and metabolic parameters, and other biochemical values in hemodialysis patients ${ }^{\mathrm{a}}$ (Continued)

\begin{tabular}{|c|c|c|c|c|}
\hline Variables & Total sample $(n=228)$ & Adequate El $(n=90)$ & Inadequate $\mathrm{El}(n=138)^{\mathrm{b}}$ & $P$ value \\
\hline Albumin, mg/dL & $4.0 \pm 0.4$ & $4.0 \pm 0.4$ & $4.0 \pm 0.4$ & 0.992 \\
\hline Albumin $\leq 3.5 \mathrm{mg} / \mathrm{dL}$ & $24(10.5)$ & $8(8.9)$ & $16(11.6)$ & 0.515 \\
\hline Pre-BUN, mg/dL & $72.9 \pm 20.9$ & $76.7 \pm 21.2$ & $70.2 \pm 20.7$ & 0.023 \\
\hline Post-BUN, mg/dL & $19.9 \pm 7.8$ & $19.0 \pm 7.6$ & $20.7 \pm 7.9$ & 0.106 \\
\hline $\mathrm{eKt} / \mathrm{N}$ & $1.6 \pm 0.3$ & $1.8 \pm 0.4$ & $1.5 \pm 0.3$ & $<0.001$ \\
\hline nPNA, g/kg & $1.4 \pm 0.4$ & $1.4 \pm 0.4$ & $1.3 \pm 0.4$ & $<0.001$ \\
\hline $\mathrm{nPNA}<1.0 \mathrm{~g} / \mathrm{kg}$ & $29(12.7)$ & $7(7.8)$ & $22(15.9)$ & 0.071 \\
\hline
\end{tabular}

CCI: Charlson comorbidity index, MET: metabolic equivalent minute/week, IDWG, interdialytic weight gains, FM: fat mass, IFG: Impaired fasting glucose, BMI: body mass index, WC: waist circumference, TG: triglyceride, HDL-C: high-density lipoprotein cholesterol, BP: blood pressure, SBP: systolic blood pressure, DBP: diastolic blood pressure, TC: total cholesterol, LDL-C: low-density lipoprotein cholesterol, FPI: fasting plasma insulin, hs-CRP: high sensitive C-reactive protein, iPTH, intact parathyroid hormone, $\mathrm{nPNA}=$ normalized protein nitrogen appearance

${ }^{a}$ Categorical data is shown as $\mathrm{n}(\%)$. Continuous data is presented as mean $\pm \mathrm{SD}$, or median (interquartile range)

${ }^{\mathrm{b}}$ Inadequate energy intake was classified as $\mathrm{El}<30 \mathrm{kcal} / \mathrm{kg} /$ day for age 60 and above; $<35$ for age less than 60

'Independent-samples T-test, Mann-Whitney $U$ test, or Chi-square tests are performed

${ }^{\mathrm{d}}$ Metabolic syndrome diagnosed by American Association of Clinical Endocrinologists (IFG plus any other abnormality: overweight/obese, high TG, low HDL, high blood pressure)

${ }^{\mathrm{e}}$ Metabolic syndrome diagnosed by Harmonizing Metabolic Syndrome (three or more abnormalities: Elevated WC, IFG, low HDL, high TG, high blood pressure)

which cause the MetS and exacerbate the dialysis outcomes [64]. On the other hand, the MetS was found to be a high-risk for many chronic health problems such as obesity, T2DM, cardiovascular diseases, cancer, and all-cause of death [16-19]. Therefore, the early MetS identification and nutritional therapy were highly recommended to reduce above adverse health problems $[25,65]$. In addition, patients who consumed adequate energy-richprotein can improve the balance of body protein, body composition which further improve hemodialysis outcomes [66].

The current study showed that about $60 \%$ of hemodialysis patients consumed low dietary energy intake. This was in the line with a reliable previous publication in which patients had at most $75 \%$ of the energy and protein intake as recommended by K/DOQI guidelines [9]. MetS prevalence was high in the present study (63.2\% AACE-MetS, 53.9\% HMetS), and in previous studies in Southern Taiwan was $61.0 \%$ measured by NCEP-ATP III criteria [15]. In comparison with previous studies, the prevalence of MetS was lower in the current study than that in a study in Brazil (74.5\%) using the HMetS criteria [27], and in United States (69.3\%) using the NCEP-ATP III criteria [67].

The consumption of PUFA and SFA did not show the significant association with MetS and its abnormalities, while the consumption of MUFA equal or greater than $20 \%$ demonstrated the association with higher IFG and AACE-MetS in the current study. In a previous study, no association between PUFA, or SFA, and MetS was found [68]. Inconsistently, a number of previous studies suggested that the consumption of dietary MUFA improves insulin sensitivity. In addition, MUFA intake as a substitution for SFA demonstrated the benefit for reducing the metabolic syndrome $[69,70]$. The discrepancy between the findings of this study and other studies could be explained by the cross-sectional design of the current study, the causal relationship is not generated. In addition, the 24-h dietary recall is subject to reporting bias from patients. In practical application, the MUFA was with high density in the Mediterranean dietary pattern (MDP). Strong evidence from several studies and trials proved that the MDP was inversely associated with the incidence of MetS, cardiovascular diseases [71-74]. Therefore, this MDP can be still encouraged and adopted in various population and cultures, with cost-effective serve for preventing the MetS and its components [75]. However, the application is with precaution and more studies are suggested to intensively investigate the MDP effect on the MetS in hemodialysis patients.

The current results illustrated that the inadequate dietary EI was associated with high prevalence of HMetS in different sub-groups. In a study conducted in Italy, the authors found that patients with MetS reported lower energy intake than those without MetS [76]. This suggested that MetS diagnosed by Harmonizing Metabolic Syndrome criteria is more sensitive than AACE-MetS in relation to energy intake. In practice, in order to improve the hemodialysis outcomes, the adequate dietary EI is recommended by the K/DOQI guidelines which can reduce the risks of MetS [9].

The present study demonstrated that the higher prevalence of IFG and AACE-MetS was observed in older patients. The association was also found in previous studies on the general population in Norway, which MetS was diagnosed by either NCEP- ATP III, or IDF criteria [60], and in individuals in the United States [61]. This emphasized that the old people are more likely to have metabolic abnormalities, risks for CVD, and type 2 
Table 2 Dietary intake among hemodialysis patients ${ }^{a}$

\begin{tabular}{|c|c|c|c|c|}
\hline Daily dietary intake ${ }^{b}$ & Total sample $(n=228)$ & Adequate El $(n=90)$ & Inadequate $\mathrm{El}(n=138)^{c}$ & $P$ value ${ }^{c}$ \\
\hline \multicolumn{5}{|l|}{ Macronutrients } \\
\hline Energy intake, kcal & $1885.0 \pm 477.2$ & $2182.6 \pm 448.9$ & $1690.9 \pm 387.7$ & $<0.001$ \\
\hline Energy intake, $\mathrm{kcal} / \mathrm{kg}$ & $31.5 \pm 8.8$ & $39.8 \pm 7.0$ & $26.1 \pm 4.6$ & $<0.001$ \\
\hline Protein, g/kg IBW & $1.2 \pm 0.3$ & $1.4 \pm 0.3$ & $1.1 \pm 0.3$ & $<0.001$ \\
\hline Protein $<1.2 \mathrm{~g} / \mathrm{kg} \mathrm{IBW}$ & $132(57.9)$ & $28(31.1)$ & $104(75.4)$ & $<0.001$ \\
\hline Protein, (\%EI) & $15.0 \pm 3.0$ & $14.6 \pm 2.7$ & $15.2 \pm 3.2$ & 0.090 \\
\hline Protein $<15 \% \mathrm{El}$ & $118(51.8)$ & $52(57.8)$ & $66(47.8)$ & 0.142 \\
\hline Carbohydrate, $g$ & $222.1 \pm 68.8$ & $252.9 \pm 71.5$ & $202.0 \pm 59.1$ & $<0.001$ \\
\hline Carbohydrate, (\%EI) & $47.6 \pm 8.6$ & $46.5 \pm 8.2$ & $48.3 \pm 8.9$ & 0.138 \\
\hline Carbohydrate < 45\%El & $80(35.1)$ & $33(36.7)$ & $47(34.1)$ & 0.687 \\
\hline Total fat, $g$ & $78.3 \pm 27.0$ & $92.5 \pm 26.5$ & $69.0 \pm 23.0$ & $<0.001$ \\
\hline Total fat, (\%El) & $37.1 \pm 7.8$ & $38.2 \pm 7.4$ & $36.4 \pm 8.1$ & 0.100 \\
\hline SFA (\%EI) & $13.4(8.0,69.4)$ & $10.6(8.0,62.9)$ & $37.9(8.5,73.7)$ & 0.083 \\
\hline $\mathrm{SFA} \geq 10 \% \mathrm{El}$ & $143(62.7)$ & $53(58.9)$ & $90(65.2)$ & 0.334 \\
\hline MUFA (\%EI) & $18.0(10.6,76.0)$ & $13.4(9.8,73.4)$ & $41.8(11.3,80.2)$ & 0.024 \\
\hline MUFA $\geq 20 \% \mathrm{El}$ & $109(47.8)$ & $34(37.8)$ & $75(54.3)$ & 0.014 \\
\hline PUFA (\%EI) & $17.6(8.7,60.6)$ & $12.2(7.6,52.0)$ & $32.8(9.6,62.9)$ & 0.015 \\
\hline PUFA $\geq 10 \% \mathrm{El}$ & $155(68.0)$ & $55(61.1)$ & $100(72.5)$ & 0.072 \\
\hline SFA/UFA ratio & $0.5 \pm 0.2$ & $0.5 \pm 0.2$ & $0.5 \pm 0.2$ & 0.869 \\
\hline UFA/SFA ratio & $2.3 \pm 0.7$ & $2.3 \pm 0.6$ & $2.3 \pm 0.8$ & 0.426 \\
\hline \multicolumn{5}{|l|}{ Micronutrients } \\
\hline \multicolumn{5}{|l|}{ Mineral and Water } \\
\hline Sodium, mg/d & $1254.8 \pm 897.6$ & $1576.9 \pm 1108.9$ & $1044.6 \pm 650.7$ & $<0.001$ \\
\hline Sodium $>1800 \mathrm{mg} / \mathrm{d}$ & $43(18.9)$ & $29(32.2)$ & $14(10.1)$ & $<0.001$ \\
\hline Fluid, $\mathrm{mL} / \mathrm{d}$ & $1382.6 \pm 480.5$ & $1493.7 \pm 506.7$ & $1310.2 \pm 449.8$ & 0.005 \\
\hline Fluid $>1500 \mathrm{~mL} / \mathrm{d}$ & $78(34.2)$ & $38(42.2)$ & $40(29.0)$ & 0.039 \\
\hline Potassium, mg/d & $1445.2 \pm 582.6$ & $1616.3 \pm 575.7$ & $1333.6 \pm 561.5$ & $<0.001$ \\
\hline Phosphate, mg/d & $694.9 \pm 257.9$ & $799.7 \pm 270.2$ & $626.6 \pm 225.6$ & $<0.001$ \\
\hline Calcium, mg/d & $291.3 \pm 177.2$ & $336.9 \pm 190.7$ & $261.6 \pm 161.6$ & 0.002 \\
\hline Iron, mg/d & $8.6 \pm 4.6$ & $9.7 \pm 5.3$ & $7.8 \pm 4.0$ & 0.003 \\
\hline Zinc, mg/d & $8.1 \pm 3.8$ & $9.3 \pm 4.0$ & $7.3 \pm 3.5$ & $<0.001$ \\
\hline \multicolumn{5}{|l|}{ Vitamins } \\
\hline Vitamin B1 (thiamin), mg/d & $0.8 \pm 0.6$ & $1.0 \pm 0.6$ & $0.8 \pm 0.6$ & 0.008 \\
\hline Vitamin B2 (riboflavin), mg/d & $0.9 \pm 0.5$ & $1.0 \pm 0.6$ & $0.8 \pm 0.5$ & 0.001 \\
\hline Niacin (B3), mg/d & $11.8 \pm 6.3$ & $13.9 \pm 7.0$ & $10.5 \pm 5.5$ & $<0.001$ \\
\hline Vitamin B6 (pyridoxine), mg/d & $1.2 \pm 0.9$ & $1.4 \pm 1.0$ & $1.0 \pm 0.7$ & 0.015 \\
\hline Vitamin B12, $\mu \mathrm{g} / \mathrm{d}$ & $3.8 \pm 3.7$ & $4.5 \pm 4.1$ & $3.4 \pm 3.4$ & 0.022 \\
\hline Vitamin C, mg/d & $90.6 \pm 63.5$ & $95.6 \pm 59.7$ & $87.3 \pm 65.8$ & 0.335 \\
\hline Vitamin $\mathrm{E}, \mathrm{mg} / \mathrm{d}^{\dagger}$ & $12.6 \pm 10.3$ & $12.9 \pm 11.1$ & $12.6 \pm 10.3$ & 0.717 \\
\hline
\end{tabular}

El: energy intake, IBW: ideal body weight, SFA: saturated fatty acid, MUFA: mono-unsaturated fatty acid, PUFA: poly-unsaturated fatty acid, UFA: unsaturated fatty acid

${ }^{a}$ Categorical data is shown as $\mathrm{n}(\%)$. Continuous data is presented as mean $\pm \mathrm{SD}$, or median (interquartile range)

${ }^{b}$ Target values recommended by Standing Committee on the Scientific Evaluation of Dietary Reference Intakes, Food and Nutrition Board, Institute of Medicine;

the European Best Practice Guideline on Nutrition and Chronic Kidney Disease; and Clinical Practice Guidelines for Nutrition in Chronic Renal Failure

Inadequate energy intake was classified as $\mathrm{El}<30 \mathrm{kcal} / \mathrm{kg} /$ day for age 60 and above; $<35$ for age less than 60

${ }^{\mathrm{d}}$ Independent-samples T-test, Mann-Whitney $\mathrm{U}$ test, or Chi-square tests are performed 


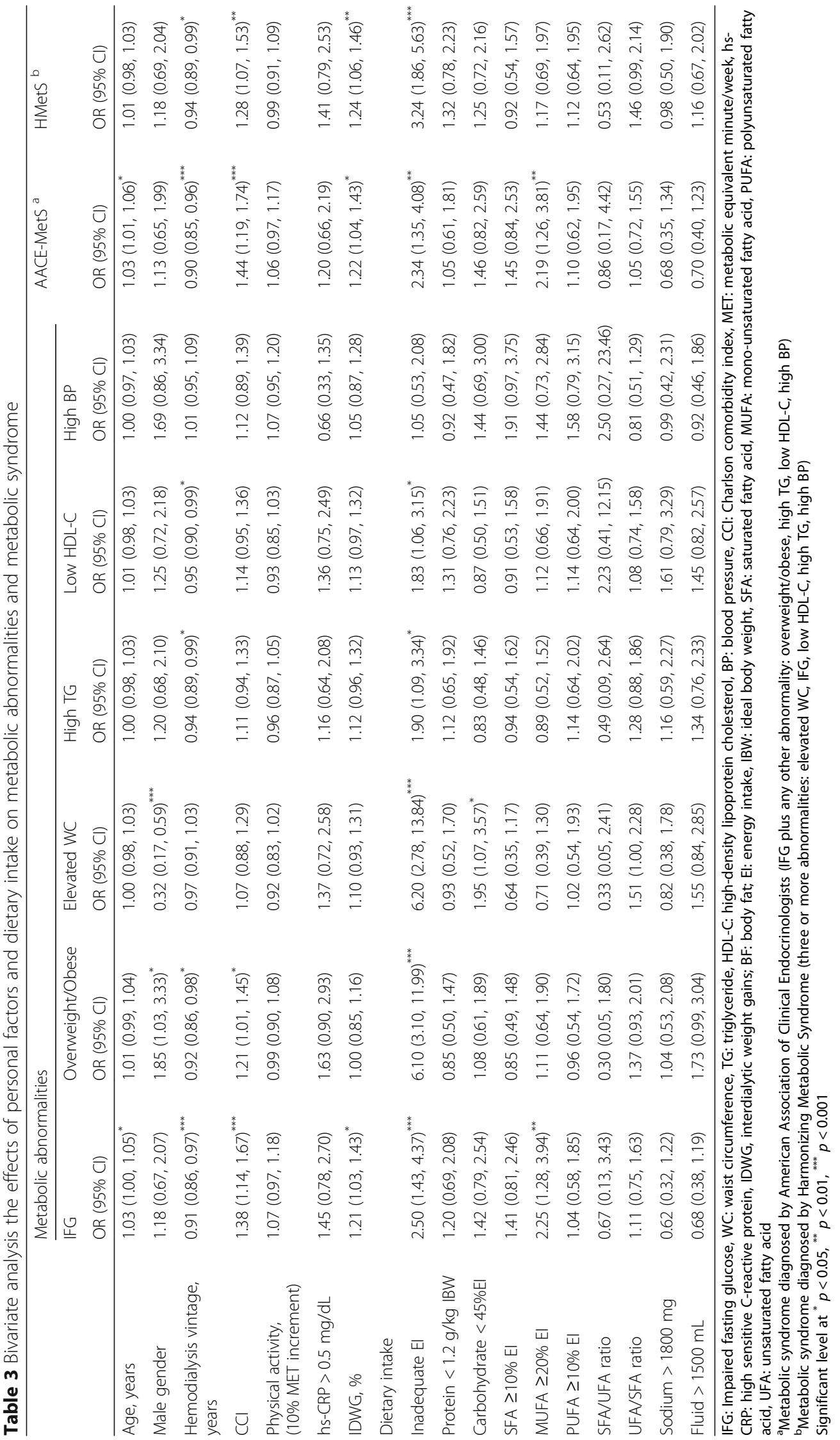




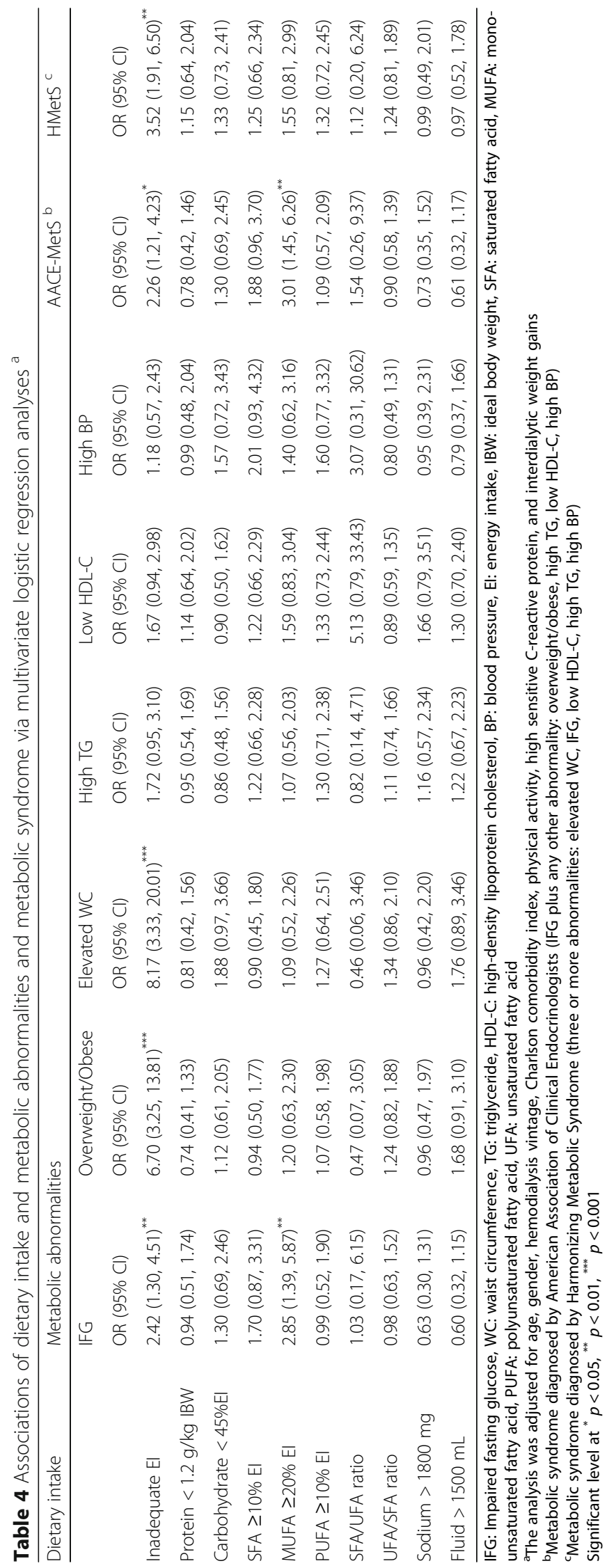


Table 5 Association between inadequate energy intake and metabolic syndrome in subgroups of medical history ${ }^{\mathrm{a}}$

\begin{tabular}{|c|c|c|c|c|c|c|c|}
\hline & Inadequate El & & AACE-MetS ${ }^{b}$ & & & HMetS $^{c}$ & \\
\hline & $(n=138)$ & $n$ & OR (95\% Cl) & $p$ & $n$ & OR (95\% Cl) & p \\
\hline Non-DM $(n=141)$ & 75 & 35 & $1.15(0.54,2.47)$ & 0.718 & 35 & $1.91(0.88,4.15)$ & 0.101 \\
\hline $\mathrm{DM}(n=87)$ & 63 & 63 & N/A & & 55 & $8.33(2.08,33.37)$ & 0.003 \\
\hline Non-HTN $(n=118)$ & 73 & 51 & $4.09(1.55,10.77)$ & 0.004 & 44 & $5.33(1.97,14.40)$ & 0.001 \\
\hline $\operatorname{HTN}(n=110)$ & 65 & 47 & $1.33(0.51,3.51)$ & 0.560 & 46 & $2.59(1.05,6.37)$ & 0.038 \\
\hline Non-CVD $(n=160)$ & 96 & 68 & $2.59(1.23,5.42)$ & 0.012 & 62 & $3.79(1.80,7.97)$ & $<0.001$ \\
\hline CVD $(n=68)$ & 42 & 30 & $1.48(0.33,6.75)$ & 0.612 & 28 & $3.64(0.99,13.36)$ & 0.052 \\
\hline
\end{tabular}

El: energy intake, DM: diabetes mellitus, HTN: hypertension, CVD: cardiovascular diseases

a The analysis was adjusted for age, gender, hemodialysis vintage, Charlson comorbidity index, physical activity, high sensitive C-reactive protein, and interdialytic weight gains

${ }^{\mathrm{b}}$ Metabolic syndrome diagnosed by American Association of Clinical Endocrinologists (IFG plus any other abnormality: overweight/obese, high TG, low HDL-C, high BP)

${ }^{c}$ Metabolic syndrome diagnosed by Harmonizing Metabolic Syndrome (three or more abnormalities: elevated WC, IFG, low HDL-C, high TG, high BP)

diabetes. Therefore, the MetS definitions should be specifically classified for elderly people, as in need of comprehensive assessment for risk factors. On the other hand, men more likely experienced overweight/obesity, but less likely had elevated waist circumference in comparison with women. This could be explained that men have greater abdominal visceral adipose tissue (likely corresponding to BMI), but less abdominal subcutaneous adipose tissue (likely corresponding to waist circumference) than women [77].

The study conducted on 153 hemodialysis patients in three dialysis centers in Tehran demonstrated that the prevalence of MetS among women was higher than that among men [62]. However, in the current study, gender was significantly associated with metabolic abnormalities, but not with AACE MetS or HMetS. This suggests that gender should take into consideration when assessing or treating patients with MetS, the presence of metabolic disorders in men or women may depend on their specific lifestyles and behaviors.

The longer hemodialysis vintage has shown the protective impact on MetS among studied hemodialysis patients. This somehow expressed the quality of hemodialysis in dialysis centers in Taiwan which reflected the effectiveness of multi-disciplinary care program in hospitals since 2003 to combat chronic kidney disease and related comorbidities [78]. In addition, the full reimbursement of dialysis costs by National Health Insurance in Taiwan medical system could further optimize the quality of care [79], which in turn reduced the prevalence of metabolic disorders in this study.

Physical activity was not associated with metabolic abnormalities or MetS in the present study. However, a review of several randomized trials concluded that the physical activity decreased the likelihood of development of MetS; if there were no contraindications, more intensive physical exercise or resistance training should be considered to prevent and treat MetS [63]. In addition, patients who performed regular exercise had better dialysis outcomes and health benefits as reported in an international study on hemodialysis patients [80].

Finally, the elevated level of hs-CRP did not show the association with MetS and its components. Inconsistently, the association was existed in the previous study, that inflammatory biomarkers had a correlation with MetS in hemodialysis patients [62]. An elevated level of hs-CRP may be a key independent predictor of adverse outcomes in hemodialysis patients with MetS. Therefore, reducing serum hs-CRP level should be considered for preventing MetS, CVD, and finally mortality among hemodialysis patients.

There was some limitations in the current study. Firstly, the causality cannot be proved between dietary EI and metabolic abnormalities and MetS in a cross-sectional design. In addition, the application of adequate EI but less MUFA intake was not clearly addressed because of the nature of the cross-sectional study design, and unavoidable reporting bias. More in-depth longitudinal studies and trials are required. The self-reported dietary assessment using food records and recalls had impacts on energy underreporting, appropriate interpretations of the results are recommended [81]. In the current study, we excluded those patients underreported their energy intake in order to avoid the bias and improve the reliability of findings [42]. However, the sample size is relatively small for subgroup analysis. Further investigation should be conducted on larger sample, to enhance the reliability of finding. The present study demonstrated a number of strengths that patients' body composition was measured precisely and directly using the BIA, while biochemical data were assessed by using standard laboratory tests. Two MetS definitions reflecting the glucocentric, obesity, and CVD risk factors were used to assure the non-spuriousness of the relationships. Future longitudinal studies or trials were recommended to 
confirm the relationship between dietary intake and MetS and impacts of nutritional interventions on dialysis outcomes.

\section{Conclusions}

This was the first study exploring the association of the reported dietary EI with metabolic abnormalities and MetS diagnosed by AACE and Harmonizing Metabolic Syndrome criteria in hemodialysis patients. We found that inadequate EI was high prevalence and associated with up to 2.26-8.17 folds of MetS and its components. Promoting adequate dietary energy intake following the $\mathrm{K} / \mathrm{DOQI}$ guidelines could help to improve dialysis quality, prevent MetS, minimize the negative effects of metabolic disorders and their consequences, in turn, optimize the quality of care, and improve the quality of life of HD patients. Future studies are suggested for carefully exploring the mechanism, and evaluating the effect of dietary energy interventions.

\section{Abbreviations}

AACE-MetS: Metabolic syndrome diagnosed by American Association of Clinical Endocrinologists; BIA: Bioelectrical impedance analysis; BMI: Body mass index; BP: Blood pressure; CCl: Charlson comorbidity index;

CVD: Cardiovascular diseases; DBP: Diastolic blood pressure; El: Energy intake; ESRD: End-stage renal disease; FPG: Fasting plasma glucose; HDL: Highdensity lipoprotein; HDL-C: High-density lipoprotein cholesterol; HMetS: Metabolic syndrome diagnosed by Harmonizing Metabolic Syndrome defined by Joint statement from the International Diabetes Federation (IDF), American Heart Association (AHA) and the National Heart, Lung, and Blood Institute (NHLBI), the World Heart Federation, the International Atherosclerosis Society, and the International Association for the Study of Obesity; hs-CRP: High sensitive C-reactive protein; IBW: Ideal body weight; IFG: Impaired fasting glucose; iPTH: Intact parathyroid hormone; LDL-C: Lowdensity lipoprotein cholesterol; MET: Metabolic equivalent minute/ week; MUFA: Mono-unsaturated fatty acid; NCEP- ATP III: National Cholesterol Education Program-Adult Treatment Panel-III definition; NKF-KDOQI: National Kidney Foundation-Kidney Disease Outcomes Quality Initiative; nPNA: Normalized protein nitrogen appearance; PUFA: Poly-unsaturated fatty acid; SBP: Systolic blood pressure;" SFA: Saturated fatty acid; TC: Total cholesterol; TG: Triglyceride; UFA: Unsaturated fatty acid; WC: Waist circumference

\section{Acknowledgments}

The authors express the appreciation to medical staff and patients from Taipei Medical University Hospital, Wan-Fang Hospital, Shuang Ho Hospital, Cathay General Hospital, and Taipei Tzu-Chi Hospital, Wei-Gong Memorial Hospital, and Lotung Poh-Ai Hospital.

\section{Funding}

The research was funded by Ministry of Science and Technology in Taiwan (NSC-102-2320-B-038-026; MOST 105-2320-B-038-033-MY3). The funder had no role in the decision to collect data, data analysis, or reporting of the results.

\section{Availability of data and materials}

The dataset used and analyzed in the current study which contains sensitive and identifying information. The authors confirm that the data is available from the corresponding author upon reasonable request.

\section{Authors' contributions}

TVD contributed to conception and design, analysis and interpretation of data, and drafted the manuscript. TCW, HHC, TWC, THC, YHH, SJP, KLK, HCL, ETL, CTS contributed to study design, acquisition of data, and involved in drafting the manuscript. CSW, IHT, YWF, TYZ contributed to acquisition of data, interpretation of data and the discussion. SHY contributed to overall study design and conception, critically revised the manuscript. All authors have read and approved the final version and the submission of the manuscript.

\section{Competing interest}

The authors have no competing interests to be declared.

\section{Ethics approval and consent to participate}

The study was approved by Taipei Medical University Joint Institutional Review Board (TMU-JIRB No. 201302024), Cathay General Hospital (CGH-OP104001), and Taipei Tzu-Chi Hospital (04-M11-090). The study procedures were also in accordance with the Helsinki Declaration of 1975, as revised in 2013 (https:// www.wma.net/policies-post/wma-declaration-of-helsinki-ethical-principles-formedical-research-involving-human-subjects/). All patients involved in the study have signed the informed consent documents on their own behalf.

\section{Consent for publication}

Not applicable.

\section{Publisher's Note}

Springer Nature remains neutral with regard to jurisdictional claims in published maps and institutional affiliations.

\section{Author details}

${ }^{1}$ School of Nutrition and Health Sciences, Taipei Medical University, No. 250 Wuxing Street, Taipei 110, Taiwan. ${ }^{2}$ Department of Nutrition and Health Sciences, Chinese Culture University, Taipei, Taiwan. ${ }^{3}$ Department of Nephrology, Taipei Medical University Hospital, Taipei, Taiwan. ${ }^{4}$ School of Medicine, Taipei Medical University, Taipei, Taiwan. ${ }^{5}$ Department of Nephrology, Taipei Medical University- Wan Fang Hospital, Taipei, Taiwan. ${ }^{6}$ Division of Nephrology, Department of Internal Medicine, Taipei Medical University- Shuang Ho Hospital, Taipei, Taiwan. 'Division of Nephrology, Cathay General Hospital, Taipei, Taiwan. ${ }^{8}$ Division of Nephrology, Taipei Tzu-Chi Hospital, Taipei, Taiwan. ${ }^{9}$ Department of Nephrology, Wei Gong Memorial Hospital, Miaoli, Taiwan. ${ }^{10}$ Department of Nephrology, Lotung Poh-Ai Hospital, Yilan, Taiwan. ${ }^{11}$ School of Public Health, Taipei Medical University, Taipei, Taiwan. ${ }^{12}$ Department of Family Medicine, Taipei Medical University Hospital, Taipei, Taiwan. ${ }^{13}$ Research Center of Geriatric Nutrition, Taipei Medical University, Taipei, Taiwan. ${ }^{14}$ Nutrition Research Center, Taipei Medical University Hospital, Taipei, Taiwan.

Received: 5 February 2018 Accepted: 10 September 2018

Published online: 19 September 2018

\section{References}

1. United States Renal Data System: International comparisons. The 2016 Annual data report: epidemiology of kidney disease in the United States: volume 2 - end-stage renal disease (ESRD) in the United States. In. USRDS Coordinating Center: National Institutes of Health, National Institute of Diabetes and Digestive and Kidney Diseases; 2016.

2. Slee AD. Exploring metabolic dysfunction in chronic kidney disease. Nutr Metab (Lond). 2012;9(1):36

3. Qian F, Korat AA, Malik V, Hu FB. Metabolic effects of monounsaturated fatty acid-enriched diets compared with carbohydrate or polyunsaturated fatty acidenriched diets in patients with type 2 diabetes: a systematic review and metaanalysis of randomized controlled trials. Diabetes Care. 2016;39(8):1448-57.

4. Kent PS, MP MC, Burrowes JD, Mc Cann L, Pavlinac J, Goeddeke-Merickel CM, Wiesen K, Kruger S, Byham-Gray L, Pace RC, et al. Academy of nutrition and dietetics and National Kidney Foundation: revised 2014 standards of practice and standards of professional performance for registered dietitian nutritionists (competent, proficient, and expert) in nephrology nutrition. J Acad Nutr Diet. 2014;114(9):1448-57.e45.

5. Schoenaker DAJM, Mishra GD, Callaway LK, Soedamah-Muthu SS. The role of energy, nutrients, foods, and dietary patterns in the development of gestational diabetes mellitus: a systematic review of observational studies. Diabetes Care. 2015;39(1):16-23.

6. Beto JA, Ramirez WE, Bansal VK. Medical nutrition therapy in adults with chronic kidney disease: integrating evidence and consensus into practice for the generalist registered dietitian nutritionist. J Acad Nutr Diet. 2014; 114(7):1077-87. 
7. Fouque D, Guebre-Egziabher F. An update on nutrition in chronic kidney disease. Int Urol Nephrol. 2007;39(1):239-46.

8. Kistler BM, Benner D, Burrowes JD, Campbell KL, Fouque D, Garibotto G, Kopple JD, Kovesdy CP, Rhee CM, Steiber A, et al. Eating during hemodialysis treatment: a consensus statement from the International Society of Renal Nutrition and Metabolism. J Ren Nutr. 2018;28(1):4-12.

9. Kopple JD. National Kidney Foundation K/DOQI clinical practice guidelines for nutrition in chronic renal failure. Am J Kidney Dis. 2001;37(1 Suppl 2):S66-70.

10. Stark S, Snetselaar L, Hall B, Stone RA, Kim S, Piraino B, Sevick MA. Nutritional intake in adult hemodialysis patients. Top Clin Nutr. 2011;26(1):45-56.

11. St-Jules DE, Woolf K, Pompeii ML, Sevick MA. Exploring problems in following the hemodialysis diet and their relation to energy and nutrient intakes: the BalanceWise study. J Ren Nutr. 2016;26(2):118-24.

12. The National Kidney Foundation Kidney Disease Outcomes Quality Initiative (K/DOQI) Workgroup. KDOQI clinical practice guidelines and clinical practice recommendations for diabetes and chronic kidney disease. Am J Kidney Dis. 2007:49(2):S12-S154.

13. Kidney Disease Outcomes Quality Initiative (K/DOQI) Group. K/DOQI clinical practice guidelines for management of dyslipidemias in patients with kidney disease. Am J Kidney Dis. 2003;41 (4 Suppl 3):S1-S91.

14. The National Kidney Foundation Kidney Disease Outcomes Quality Initiative (K/DOQI) Workgroup. K/DOQI clinical practice guidelines on hypertension and antihypertensive agents in chronic kidney disease. Am J kidney dis. 2004;43. Supplement. 1:11-3.

15. Tu S-F, Chou Y-C, Sun C-A, Hsueh S-C, Yang T. The prevalence of metabolic syndrome and factors associated with quality of Dialysis among hemodialysis patients in southern Taiwan. Glob J Health Sci. 2012;4(5):53-62.

16. Mottillo S, Filion KB, Genest J, Joseph L, Pilote L, Poirier P, Rinfret S, Schiffrin EL, Eisenberg MJ. The metabolic syndrome and cardiovascular risk. A Systematic Review and Meta-Analysis J Am Coll Cardiol. 2010; 56(14):1113-32.

17. Sattar N, McConnachie A, Shaper AG, Blauw GJ, Buckley BM, de Craen AJ, Ford I, Forouhi NG, Freeman DJ, Jukema JW, et al. Can metabolic syndrome usefully predict cardiovascular disease and diabetes? Outcome data from two prospective studies. Lancet. 2008;371(9628):1927-35.

18. Kastorini CM, Panagiotakos DB, Georgousopoulou EN, Laskaris A, Skourlis N, Zana A, Chatzinikolaou C, Chrysohoou C, Puddu PE, Tousoulis D, et al. Metabolic syndrome and 10-year cardiovascular disease incidence: the ATTICA study. Nutr Metab Cardiovasc Dis. 2016;26(3):223-31.

19. Harding J, Sooriyakumaran M, Anstey K, Adams R, Balkau B, Briffa T, Davis TME, Davis WA, Dobson A, Giles GG, et al. The metabolic syndrome and cancer: is the metabolic syndrome useful for predicting cancer risk above and beyond its individual components? Diabetes Metab. 2015;41(6):463-9.

20. Vogt BP, Souza PL, Minicucci MF, Martin LC, Barretti P, Caramori JT. Metabolic syndrome criteria as predictors of insulin resistance, inflammation, and mortality in chronic hemodialysis patients. Metab Syndr Relat Disord. 2014;12(8):443-9.

21. Einhorn D, Reaven GM, Cobin RH, Ford E, Ganda OP, Handelsman Y, Hellman R, Jellinger PS, Kendall D, Krauss RM, et al. American College of Endocrinology position statement on the insulin resistance syndrome. Endocr Pract. 2003;9(3):237-52

22. Alberti KGMM, Eckel RH, Grundy SM, Zimmet PZ, Cleeman Jl, Donato KA, Fruchart J-C, James WPT, Loria CM, Smith SC, et al. Harmonizing the metabolic syndrome: a joint interim statement of the international diabetes federation task force on epidemiology and prevention; National Heart, Lung, and Blood Institute; American Heart Association; world heart federation; international atherosclerosis society; and International Association for the Study of obesity. Circulation. 2009;120(16):1640-5.

23. Martins AM, Dias Rodrigues JC, de Oliveira Santin FG, Barbosa Brito FdS, Bello Moreira AS, Lourenço RA, Avesani CM. Food intake assessment of elderly patients on hemodialysis. J Ren Nutr 2015;25(3):321-326.

24. Shah A, Bross R, Shapiro BB, Morrison G, Kopple JD. Dietary energy requirements in relatively healthy maintenance hemodialysis patients estimated from long-term metabolic studies. Am J Clin Nutr. 2016; 103(3):757-65

25. Azadbakht L, Mirmiran P, Esmaillzadeh A, Azizi T, Azizi F. Beneficial effects of a dietary approaches to stop hypertension eating plan on features of the metabolic syndrome. Diabetes Care. 2005;28(12):2823-31.

26. Daniel WW, Cross CL. Biostatistics: A Foundation for analysis in the health sciences, 10th ed. New York, United States of America: John Wiley \& Sons; 2013.
27. Vogt BP, Ponce D, Caramori JCT. Anthropometric indicators predict metabolic syndrome diagnosis in maintenance hemodialysis patients. Nutr Clin Pract. 2016;31(3):368-74.

28. Pourhoseingholi MA, Vahedi M, Rahimzadeh M. Sample size calculation in medical studies. Gastroenterol Hepatol Bed Bench. 2013;6(1):14-7.

29. Wong T-C, Chen Y-T, Wu P-Y, Chen T-W, Chen H-H, Chen T-H, Hsu Y-H, Yang S-H. Ratio of dietary $\omega-3$ and $\omega-6$ fatty acids-independent determinants of muscle mass - in hemodialysis patients with diabetes. Nutrition. 2016;32(9):989-94.

30. Duong TV, Wong T-C, Chen H-H, Chen T-W, Chen T-H, Hsu Y-H, Peng S-J, Kuo K-L, Wang C-S, Tseng IH, et al. The cut-off values of dietary energy intake for determining metabolic syndrome in hemodialysis patients: a clinical cross-sectional study. PLoS One. 2018;13(3):e0193742.

31. Duong TV, Wong T-C, Su C-T, Chen H-H, Chen T-W, Chen T-H, Hsu Y-H, Peng S-J, Kuo K-L, Liu H-C, et al. Associations of dietary macronutrients and micronutrients with the traditional and nontraditional risk factors for cardiovascular disease among hemodialysis patients: a clinical crosssectional study. Medicine (Baltimore). 2018;97(26):e11306.

32. Wong T-C, Su H-Y, Chen Y-T, Wu P-Y, Chen H-H, Chen T-H, Hsu Y-H, Yang S$\mathrm{H}$. Ratio of C-reactive protein to albumin predicts muscle mass in adult patients undergoing hemodialysis. PLoS One. 2016;11(10):e0165403.

33. Hemmelgarn BR, Manns BJ, Quan H, Ghali WA. Adapting the Charlson comorbidity index for use in patients with ESRD. Am J Kidney Dis. 2003; 42(1):125-32.

34. Wong T-C, Chen Y-T, Wu P-Y, Chen T-W, Chen H-H, Chen T-H, Yang S-H. Ratio of dietary $n-6 / n-3$ polyunsaturated fatty acids independently related to muscle mass decline in hemodialysis patients. PLoS One. 2015;10(10): e0140402.

35. Okorodudu DO, Jumean MF, Montori VM, Romero-Corral A, Somers VK, Erwin PJ, Lopez-Jimenez F. Diagnostic performance of body mass index to identify obesity as defined by body adiposity: a systematic review and meta-analysis. Int J Obes. 2010;34:791-9.

36. Ipema KIR, Kuipers J, Westerhuis R, Gaillard CAJM, van der Schans CP, Krijnen WP, Franssen CFM. Causes and consequences of Interdialytic weight gain. Kidney Blood Press Res. 2016;41(5):710-20.

37. Liou YM, Jwo CJC, Yao KG, Chiang L-C, Huang L-H. Selection of appropriate Chinese terms to represent intensity and types of physical activity terms for use in the Taiwan version of IPAQ. J Nurs Res. 2008;16(4):252-63.

38. Craig CL, Marshall AL, Sjöström M, Bauman AE, Booth ML, Ainsworth BE, Pratt M, Ekelund U, Yngve A, Sallis JF, et al. International physical activity questionnaire: 12-country reliability and validity. Med Sci Sports Exerc. 2003; 35(8):1381-95.

39. Lee PH, Macfarlane DJ, Lam TH, Stewart SM. Validity of the international physical activity questionnaire short form (IPAQ-SF): a systematic review. Int J Behav Nutr Phys Act. 2011;8:115.

40. Chiu Y-F, Chen Y-C, Wu P-Y, Shih C-K, Chen H-H, Chen H-H, Chen T-H, Yang S$\mathrm{H}$. Association between the hemodialysis eating index and risk factors of cardiovascular disease in hemodialysis patients. J Ren Nutr. 2014;24(3):163-71.

41. Shapiro BB, Bross R, Morrison G, Zadeh K, Kopple JD. Self-reported, interview-assisted diet records underreport energy intake in maintenance hemodialysis patients. J Ren Nutr. 2015;25(4):357-63.

42. Hirvonen T, Männistö S, Roos E, Pietinen P. Increasing prevalence of underreporting does not necessarily distort dietary surveys. Eur I Clin Nutr. 1997;51(5):297-301.

43. McDoniel SO. Systematic review on use of a handheld indirect calorimeter to assess energy needs in adults and children. Int I Sport Nutr Exerc Metab. 2007;17(5):491-500.

44. Nieman DC, Trone GA, Austin MD. A new handheld device for measuring resting metabolic rate and oxygen consumption. J Am Diet Assoc. 2003; 103(5):588-92

45. St-Onge M-P, Rubiano F, Jones A, Heymsfield SB. A new hand-held indirect calorimeter to measure postprandial energy expenditure. Obes Res. 2004; 12(4):704-9.

46. Hasson RE, Howe CA, Jones BL, Freedson PS. Accuracy of four resting metabolic rate prediction equations: effects of sex, body mass index, age, and race/ethnicity. J Sci Med Sport. 2011;14(4):344-51.

47. Wu P-Y, Yang S-H, Wong T-C, Chen T-W, Chen H-H, Chen T-H, Chen Y-T. Association of Processed Meat Intake with hypertension risk in hemodialysis patients: a cross-sectional study. PLoS One. 2015;10(10):e0141917.

48. Daugirdas JT. Simplified equations for monitoring Kt $N$, PCRn, eKt $/$, and ePCRn. Adv Ren Replace Ther. 1995;2(4):295-304. 
49. Shaw JE, Zimmet PZ, Alberti KGMM. Point: impaired fasting glucose: the case for the new American Diabetes Association criterion. Diabetes Care. 2006;29(5):1170-2.

50. Hwang L-C, Bai C-H, Chen C-J. Prevalence of obesity and metabolic syndrome in Taiwan. J Formos Med Assoc. 2006;105(8):626-35.

51. Expert Panel on Detection Evaluation and Treatment of High Blood Cholesterol in Adults. Executive summary of the third report of the national cholesterol education program (NCEP) expert panel on detection, evaluation, and treatment of high blood cholesterol in adults (adult treatment panel III). JAMA. 2001;285(19):2486-97.

52. Omae K, Kondo T, Tanabe K. High preoperative C-reactive protein values predict poor survival in patients on chronic hemodialysis undergoing nephrectomy for renal cancer. Urol Oncol 2015;33(2):67.e9-e13.

53. McAuley KA, Williams SM, Mann JI, Walker RJ, Lewis-Barned NJ, Temple LA, Duncan AW. Diagnosing insulin resistance in the general population. Diabetes Care. 2001:24(3):460-4.

54. Ascaso JF, Pardo S, Real JT, Lorente Rl, Priego A, Carmena R. Diagnosing insulin resistance by simple quantitative methods in subjects with normal glucose metabolism. Diabetes Care. 2003;26(12):3320-5.

55. Kidney Disease. Improving global outcomes (KDIGO) CKD-MBD work group. KDIGO clinical practice guideline for the diagnosis, evaluation, prevention, and treatment of chronic kidney disease-mineral and bone disorder (CKDMBD). Kidney Int. 2009;76(Suppl 113):S1-S130.

56. Lopes AA, Bragg-Gresham JL, Elder SJ, Ginsberg N, Goodkin DA, Pifer T, Lameire N, Marshall MR, Asano Y, Akizawa T, et al. Independent and joint associations of nutritional status indicators with mortality risk among chronic hemodialysis patients in the Dialysis outcomes and practice patterns study (DOPPS). J Ren Nutr. 2010;20(4):224-34.

57. Shapiro SS, Wilk MB. An analysis of variance test for normality (complete samples). Biometrika. 1965;52(3/4):591-611.

58. Razali NM, Wah YB. Power comparisons of shapiro-wilk, kolmogorovsmirnov, lilliefors and Anderson-darling tests. Journal of Statistical Modeling and Analytics. 2011;1(1):21-3.

59. Sicras-Mainar A, Ruíz-Beato E, Navarro-Artieda R, Maurino J. Comorbidity and metabolic syndrome in patients with multiple sclerosis from Asturias and Catalonia, Spain. BMC Neurol. 2017;17:134.

60. Hildrum B, Mykletun A, Hole T, Midthjell K, Dahl AA. Age-specific prevalence of the metabolic syndrome defined by the international diabetes federation and the National Cholesterol Education Program: the Norwegian HUNT 2 study. BMC Public Health. 2007;7:220-9.

61. Razzouk L, Muntner P. Ethnic, gender, and age-related differences in patients with the metabolic syndrome. Curr Hypertens Rep. 2009;11(2):127-32.

62. Shahrokh S, Heydarian P, Ahmadi F, Saddadi F, Razeghi E. Association of Inflammatory Biomarkers with metabolic syndrome in hemodialysis patients. Ren Fail. 2012;34(9):1109-13.

63. Lakka TA, Laaksonen DE. Physical activity in prevention and treatment of the metabolic syndrome. Appl Physiol Nutr Metab. 2007;32(1):76-88.

64. Cuppari L, Ikizler TA. Energy balance in advanced chronic kidney disease and end-stage renal disease. Semin Dial. 2010;23(4):373-7.

65. Beto JA, Bansal VK. Medical nutrition therapy in chronic kidney failure: integrating clinical practice guidelines. J Am Diet Assoc. 2004;104(3):404-9.

66. Veeneman JM, Kingma HA, Boer TS, Stellaard F, De Jong PE, Reijngoud D-J, Huisman RM. Protein intake during hemodialysis maintains a positive whole body protein balance in chronic hemodialysis patients. Am J Physiol Endocrinol Metab. 2003;284(5):E954-E65.

67. Young DO, Lund RJ, Haynatzki G, Dunlay RW. Prevalence of the metabolic syndrome in an incident dialysis population. Hemodial Int. 2007;11(1):86-95.

68. Um Y-J, Oh S-W, Lee C-M, Kwon H-T, Joh H-K, Kim Y-J, Kim H-J, Ahn S-H. Dietary fat intake and the risk of metabolic syndrome in Korean adults. Korean J Fam Med. 2015;36(5):245-52.

69. Gillingham LG, Harris-Janz S, Jones PJH. Dietary monounsaturated fatty acids are protective against metabolic syndrome and cardiovascular disease risk factors. Lipids. 2011;46(3):209-28.

70. Riccardi G, Giacco R, Rivellese AA. Dietary fat, insulin sensitivity and the metabolic syndrome. Clin Nutr. 2004;23(4):447-56.

71. Esposito K, Maiorino MI, Ceriello A, Giugliano D. Prevention and control of type 2 diabetes by Mediterranean diet: a systematic review. Diabetes Res Clin Pract. 2010;89(2):97-102

72. Koloverou E, Esposito K, Giugliano D, Panagiotakos D. The effect of Mediterranean diet on the development of type 2 diabetes mellitus: a meta-analysis of 10 prospective studies and 136,846 participants. Metabolism. 2014;63(7):903-11.
73. Martínez-González MÁ, Martín-Calvo N. The major European dietary patterns and metabolic syndrome. Rev Endocr Metab Disord. 2013;14(3):265-71.

74. Calton EK, James AP, Pannu PK, Soares MJ. Certain dietary patterns are beneficial for the metabolic syndrome: reviewing the evidence. Nutr Res. 2014;34(7):559-68

75. Kastorini C-M, Milionis HJ, Esposito K, Giugliano D, Goudevenos JA, Panagiotakos DB. The Effect of Mediterranean Diet on Metabolic Syndrome and its Components: A Meta-Analysis of 50 Studies and 534,906 Individuals. J Am Coll Cardiol. 2011;57(11):1299-313.

76. Buscemi S, Verga S, Donatelli M, D'Orio L, Mattina A, Tranchina MR, Pizzo G, Mulè G, Cerasola G. A low reported energy intake is associated with metabolic syndrome. J Endocrinol Investig. 2009;32(6):538-41.

77. Maki KC, Rains TM, Bell M, Reeves MS, Farmer MV, Yasunaga K. Fat mass, abdominal fat distribution, and C-reactive protein concentrations in overweight and obese men and women. Metab Syndr Relat Disord. 2011: 9(4):291-6.

78. Chen Y-R, Yang Y, Wang S-C, Chiu P-F, Chou W-Y, Lin C-Y, Chang J-M, Chen T-W, Ferng S-H, Lin C-L. Effectiveness of multidisciplinary care for chronic kidney disease in Taiwan: a 3-year prospective cohort study. Nephrol Dial Transplant. 2013;28(3):671-82.

79. Cheng T-M. Reflections on the 20th anniversary of Taiwan's single-payer National Health Insurance System. Health Aff. 2015:34(3):502-10.

80. Tentori F, Elder SJ, Thumma J, Pisoni RL, Bommer J, Fissell RB, Fukuhara S, Jadoul M, Keen ML, Saran R, et al. Physical exercise among participants in the Dialysis outcomes and practice patterns study (DOPPS): correlates and associated outcomes. Nephrol Dial Transplant. 2010;25(9):3050-62.

81. Subar AF, Freedman LS, Tooze JA, Kirkpatrick SI, Boushey C, Neuhouser ML, Thompson FE, Potischman N, Guenther PM, Tarasuk V, et al. Addressing current criticism regarding the value of self-report dietary data. J Nutr. 2015; 145(12):2639-45.
Ready to submit your research? Choose BMC and benefit from:

- fast, convenient online submission

- thorough peer review by experienced researchers in your field

- rapid publication on acceptance

- support for research data, including large and complex data types

- gold Open Access which fosters wider collaboration and increased citations

- maximum visibility for your research: over $100 \mathrm{M}$ website views per year

At BMC, research is always in progress.

Learn more biomedcentral.com/submissions 